\title{
9 \\ The Politics of the Baining \\ Fire Dance
}

\section{Naomi Faik-Simet}

Papua New Guinea is undergoing changes to many of its cultural forms, including dance. With the increase in demand on traditional forms of art for display in modern occasions, a good number of traditional dances have become special features in such new contexts. These contexts are commonly referred to as 'shows' and 'festivals', which contribute to the exposure of some of the country's special dance performances. One such performance that has become popular amongst festival organisers, spectators, and tourists is the Baining 'fire dance'.

The fire dance is sketched in this chapter, which articulates the challenges of the politics of its performances in various performance spaces. This chapter raises concerns about the use of this dance in hybridised settings, as well as issues of ownership amongst the traditional custodians and festival organisers at the provincial and national levels.

Elaborate accounts of Baining cultural and social life by anthropologist Jane Fajans provide information on the description and historical development of the fire dance. Fajans's work is used here as a main reference to understand and compare the politics and function of the fire dance from the past to the present. In addition to Fajans, accounts by Karl Hesse and Theo Aerts also provide insights into Baining spiritual and cultural life. 
This chapter aims to enunciate the status of the Baining fire dance in the contemporary and modern contexts of today and consider whether such changes in time and space have affected its indigenous cultural form - a case that is prevalent with many Papua New Guinea traditional dances. This study further highlights the role by cultural leaders and leaders at the provincial and national level who are responsible and mandated by the government of Papua New Guinea to safeguard and promote the indigenous cultures of this country. The Baining case has been an ongoing issue amongst show organisers and has become quite controversial at the political level thus it has been chosen for discussion in this chapter.

\section{Background}

The Baining are the original inhabitants of the Gazelle Peninsula of East New Britain Province in Papua New Guinea. Linguistically, the Baining speak different languages from those of the Tolai and Pomio people who are part of the same province. According to Lewis, Simons, and Fennig (2013), the Baining language family consists of six languages within the Gazelle Peninsula area: Kairak, Makolkol (extinct), Mali, Qaqet, Simbali, and Ura (Figure 1). These six language groups are also referred to as the main clan groups, which exist in the north, central, and south Baining areas. These language groups are not located in only one part of the Baining area, but are distributed throughout the north to the south Baining through intermarriage and the movement of people in search for land for gardening and other social activities.

The fire dance originated with Qaqet in the north Baining area and was known locally as atut, while the central and south Baining areas have other local names for the dance. For instance, in the central Baining area, the Kairaks refer to the fire dance as qavet (mask). Masks are an important feature of the fire dance, and their designs distinguish and identify them as belonging to a certain clan group.

Although the Baining are the original people of the region, they have the smaller population than the Tolai and Pomio. The Tolai live mostly on the Gazelle Peninsula in the east, while the Pomio live in the southwest, as shown in Figure 1. The lower population amongst the Baining is the result of their being dominated by the Tolai, who inhabited most of their land and attacked the Baining in the process. 


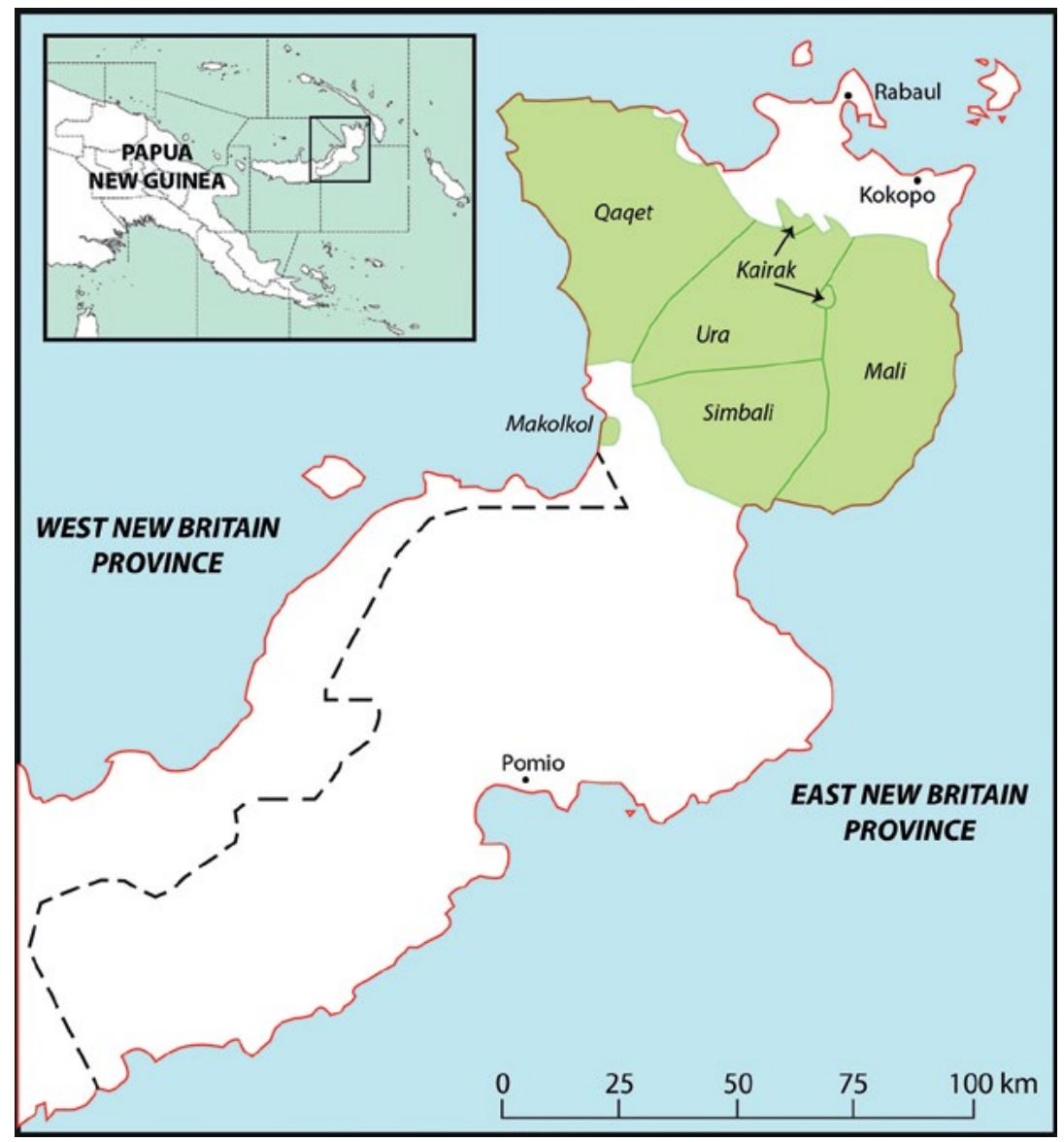

Figure 1. The six Baining languages in the Gazelle Peninsula area of East New Britain Province: Kairak, Makolkol (extinct), Mali, Qaqet, Simbali, and Ura

Source: Map adapted from Ethnologue (Lewis, Simons, and Fennig 2013) by Don Niles

Due to differences among the Baining and Tolai people, the Baining moved further into the hinterland. Occupying primarily rather remote parts of East New Britain, the Baining mostly continue their life and daily activity in isolation. For a long time they distrusted the Tolai and preferred to have very little to do with them. Given this situation, Baining culture was kept hidden in the hills and remained relatively unknown to others. Their various rites and rituals, including their dance performances were only known within their own territory and in the peripheries, such as Gaulim, located in the foothills of the Baining mountains, and Malasaet station in the north Baining area. 
It was not until the early 1960s that the Baining became visible in Rabaul and Kokopo towns to pursue the sale of their crops such as cocoa during the flush period. The 'flush period' describes the time when cocoa farmers benefited a great deal from the sale of cocoa, making the cash crop a main source of income for the local people. In these early years, they continued to be timid and fearful of the Tolai and others with whom they came into contact. During this time also, some of the Baining left their mountain homes and came down to the coast to work for the Tolai. In this way, many of them were able to live among the Tolai for some time before returning to their homes in the mountains.

\section{The Baining fire dance}

Following the gradual movement of the Baining into the Gazelle and along the coast, they started to interact more frequently with the Tolai and others in the urban centres. This development saw the exposure of the Baining fire dance or atut as described here by Fajans:

The drama and excitement of a Baining Fire Dance attain an extraordinary level. The scene consists of phantasmagoric masks flitting in and out of the shadows created by an enormous fire in the middle of a clearing. The dancers are accompanied by a chorus of male singers who sing in an extremely rapid falsetto style with a kind of yodeling refrain; they accompany themselves with hollow bamboo tube instruments. The scene is periodically shattered and at the same time highlighted as one or more dancers jump into and run across the fire sending sparks and coals cascading into the dancers', and even the spectators' zones. (Fajans 1985: 434)

Fajans further describes the Baining fire dance as 'play' that has no direct connection to Baining life. It is not ritualistic and does not seem to follow a set behavioural pattern. Past anthropologists, such as Gregory Bateson and Jean Poole, also conducted studies on aspects of the Baining culture, but did not thoroughly analyse the connection of the Baining way of life to their dances, masks, and songs, including the atut.

Many are attracted to the Baining fire dance, performed only by men, because of its unique performance style. The performance occurs at night and although it appears to be associated with a ritual, it does not have direct relevance to a traditional occasion or ceremony. It is a performance that imitates spiritual beings, which are described in the songs and dance 
movements. Performed around the fire, the dancers skip in a rush and in short sequence around the fire. The dance sequence involves the stamping and twisting of feet in time to the song melody and the sounds of the rattles worn on their body. Aimed at drawing attention, the dancers dash into the fire and are seen dancing among the burning wood, which is eventually reduced to ashes by the action of stamping. As such, the fire dance is a spectacular performance that draws attention to its dancers.

Karl Hesse and Theo Aerts give a clear description of the connection between the Baining physical and spiritual life, and how this relationship is projected in the fire dance:

The meaning of feasts and dances is a treasure specially kept and nurtured by the elders of the tribe, by those fully initiated in the lore of their ancestors ... The great days are for them, occasions to remind the younger generations, and the women in general that they themselves stay in close relationship with the spirits, that they have the power to call them and to chase them away, and even to use them in inflicting sickness and death. Such an invisible belief needs expression, and the great dances are exactly the way to express the belief in protecting and avenging spirits, who are so intimately associated with one's everyday life. It is even said that, on the day the Bainings make their masks or dance with them, the spirits too perform these activities ... everything one can think of is related to the spirits and becomes visible in the dances. (Hesse and Aerts 1996 [1982]: 41)

This citation confirms the role of the fire dance in mediating between the spiritual and physical worlds. Known for its elaborate costume and rich tradition, the fire dance continues to mesmerise spectators in its various performance spaces today.

\section{Costume}

An outstanding element of the fire dance is its mask costume, which takes a great amount of time to prepare. Fajans (1985) reports that there are three types of mask associated with the atut: avriski, anguangi (atutki), and alaspraka. Each comprises a different type of headdress with elaborate designs. These are briefly considered below. 


\section{Avriski}

Further described by Fajans, the 'avriski is the simplest headdress which consists of a cone shaped hat with a brim'. A stick known as avulvulka is stuck out from the top and is decorated with feathers. It is usually structured together with three-dimensional design from 'abstract (circles, triangles) to realistic (e.g. fish, bird, helicopter, etc.). The brim of the hat is fringed with pandanus leaves' (Fajans 1985: 440). These designs illustrate the complex art found in the Baining culture, which remains remarkable to this day. The mask and headdress are important in demarcating a clan's identity and origin.

\section{Anguangi}

Anguangi or atutki headdresses are more like helmet masks that dancers wear to cover their heads, only revealing their mouths and eyes. These masks are more naturalistic in configuration than either of the other two. They frequently appear to represent the heads of animals or other creatures, although it is believed that these creatures are imaginary. The most striking features of these masks are the eyes and mouths.

\section{Alaspraka}

As described by Fajans, the alaspraka is the 'most bizarre. It is a composite of a helmet mask similar to the anguangi $\ldots$ with a pair of huge rectangular frames like billboards, which ... are hung on the sides of the mask, completely obscuring the helmet mask within except when seen directly from front or back' (Fajans 1985: 444).

Hesse and Aerts present another description that differs from the above three examples of the Baining mask as described by Fajans. These masks are also said to be associated with the Baining fire dance:

The night dancers wear special masks, which can be divided into two main groups: the headmasks (a ningum; plural: a ningap), and the so called 'cobweb-masks' (a vurbracha; plural: vurvet). Normally a cobweb-mask opens and closes the dancing. If there are more of these they also appear interspersed among the appearances of the other masks. (Hesse and Aerts 1996 [1982]: 69) 


\section{Emergence in new spaces}

Over the years, the Baining fire dance began to gain popularity outside of its traditional territory of performance. It started to appear at mission stations and schools as part of commemoration ceremonies. Emanating from these new settings, the dance gradually started appearing in local shows, festivals, and other celebrations within the province. In many of these events, they quickly became popular and were the highlights at these various occasions. The performance was clearly a new spectacle, not only for the coastal Tolai, but also for others residing in the province and visitors. The Baining fire dance created awe and curiosity from spectators who were not familiar with Baining culture.

In the early years of their coming into the public and open performances, the fire dancers enjoyed the popularity befitting novel cultural items in the East New Britain Province. Following this development, demands came forth from show and festival organisers to have the fire dance performed for local, national, and international festivals as a draw card and national symbol for East New Britain and Papua New Guinea.

As the popularity of the Baining fire dance grew, the demand by local and international spectators also grew. On a larger scale, the Baining dancers were invited to perform in Tokyo, Japan, in 1986. This was through an arrangement by Paivu Tours operated by Meli Paivu, a prominent business man in Rabaul. During 2000-14, invitations were sent to the Baining to perform the fire dance at special occasions in places such as Port Moresby and the 2006 National Mambu and Garamut Festival in Wewak, East Sepik Province. During the same year, they performed in Port Moresby during the Cultural Night held for delegates at the meeting of the African, Caribbean, and Pacific Group and the European Union (ACP-EU). More recently, Baining fire dancers participated under the special feature category for Papua New Guinea performances at the 5th Melanesian Festival of Arts and Culture held in Port Moresby in 2014.

In East New Britain, the fire dance was popularised by the Tolai Warwagira Festival held in the province during the mid-1960s and then later by the National Mask Festival, beginning in 2000. As part of the National Cultural Commission's aim to preserve and promote Papua New Guinea's indigenous cultures, the commission initiated the regional National Mask festivals. Following this development, the National Mask Festival staged in East New Britain Province was combined with the earlier 
Tolai Warwagira Festival to create one event for festival participants and spectators (Jacob Simet, interview, 2015). This event became a main draw card, together with tubuan canoe dance, known as the kinavai, performed by the Tolai. These two cultural elements became synonymous with the festival, so much so that the festival could not happen without them. Other special events in the province profiled these performances and referred to them as iconic, as reported in The National daily newspaper (5 April 2016; see Figure 2). The two cultural performances were given prominent places in the festival and were publicised far and wide. It was understood that many people who came to the festival, including tourists from overseas, were drawn by these two events. Consequently, festival organisers had to make sure that the performances did take place in order to avoid disappointments by festival attendees.

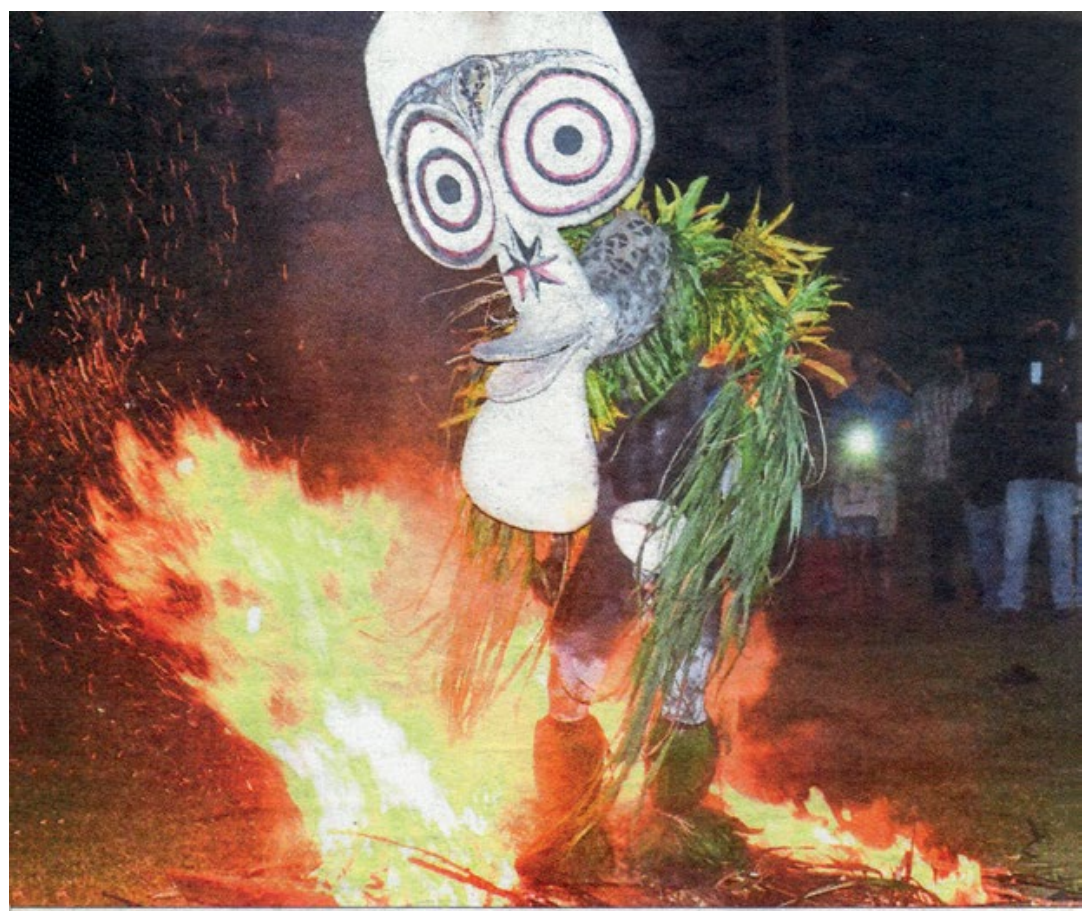

Baining fire dance ... Baining fire dancers from Gazelle, East New Britain, come arounc once a while to perform during special occasions. Pictured is a dancer from Main village in the Gaulim area among several dancers who performed last Saturday night at the Ralum Club to start a fundraisel and corporate dinner for the Maravut Resource Centre at Nonga Base Hospital. Baining and Tubuar masks from Pomio, Gazelle, Rabaul and Kokopo districts are traditional icons of the province. They are restricted from performing outside the province.

Figure 2. Baining fire dance in The National newspaper

Source: The National, 5 April 2016 
Capitalising on the popularity of the fire dancers, which had been built up by the festival, tour operators in the province promoted and encouraged the Baining fire dance at the national and international level. As a result, the performance became a sought-after item on festival programmes, together with other mask dances in the province such as the kinavai dance. Many tour operators in East New Britain built their tour packages around the fire dance alone.

\section{Ownership}

For many Baining performances, ownership was not so much of an issue. As mentioned above, the atut was originally performed by the people of the north Baining; eventually through the movement of people and other social factors, the atut has spread to the central and southern part of the Baining area. Ownership of the fire dance does not lie with an individual, but is commonly with a clan. The clan leader is bestowed the authority to permit the performance of the fire dance for any occasion. Consent for the use of the fire dance has to be given by the clan leader for any performance purpose. For instance, in Ivere in the central Baining area, the fire dance is owned by each sub-clan. During an interview with Jonah Todi Irka (leader of the Vir sub-clan of the Kairak language group; see Figure 3), he confirmed that ownership is now an important issue among the Baining and may cause problems at the community level if proper consent for performance of the fire dance is not sought from the appropriate clan. He further shared his experience of taking the qavet (as the fire dance is called in his language) to perform at the 1980 South Pacific Festival of Arts in Port Moresby and the 2014 Melanesian Festival of Arts and Culture in Port Moresby (see Figure 4). Irka said it was not an issue for them taking the fire dance to perform at these occasions as he followed cultural protocols and obtained the consent from members of his clan to perform the fire dance outside of its traditional contexts. 


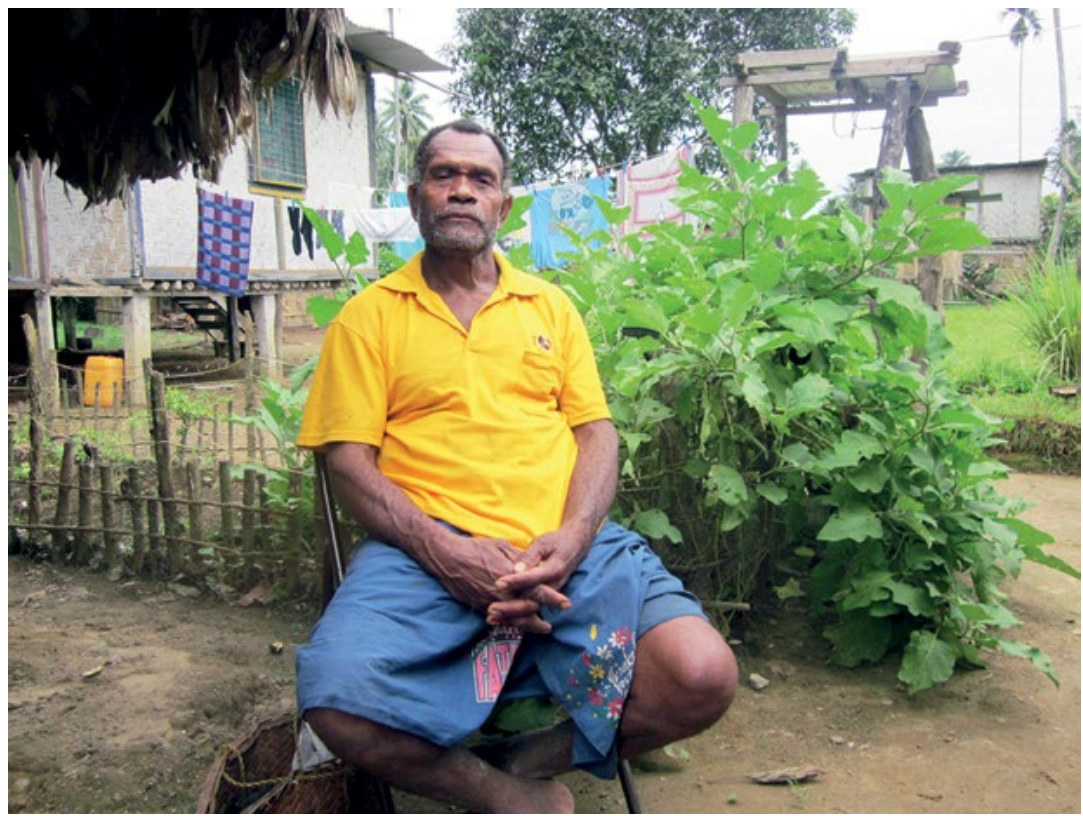

Figure 3. Jonah Todi Irka, leader of Vir sub-clan, in the Kairak area, Ivere ward, central Baining

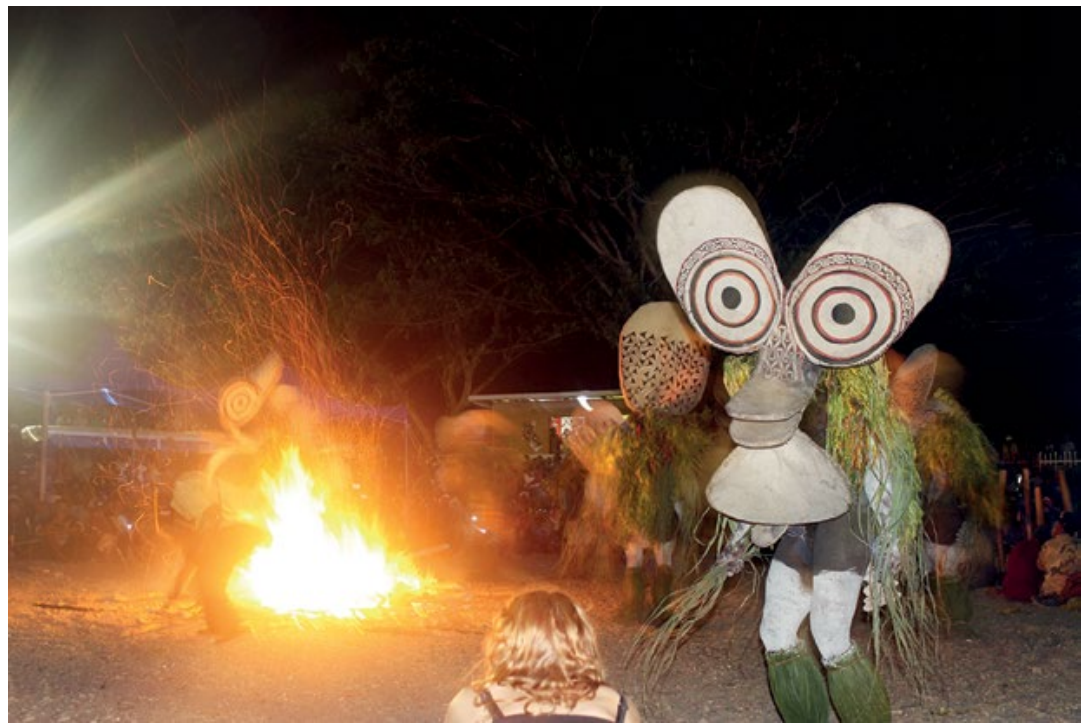

Figure 4. Baining fire dancer during the 5th Melanesian Festival of Arts and Culture in Port Moresby, 2014

Source: Gedisa Jacob 
More recently, a challenge faced by the clan leaders resulted in the establishment of another body called the Qaket Stewardship Council. This council was set up in the late 1980s, and its members comprise leaders of each clan. It was established to protect the rights of the indigenous Baining and have their dances and culture protected from exploitation and abuse. Although the Council was set up with good intentions, other members were compromising with outsiders, releasing valuable information to non-Baining people, especially tourists, about their rituals and culture. This has raised concerns amongst some individual clan leaders who tend to independently make decisions on the use of their fire dance without consulting the council. Another factor threatening the existence of the Baining fire dance is the influx of different church groups condemning beliefs associated with it and its practice. This is a growing concern in the area and has led to a good number of clan leaders taking individual ownership in regulating the performance of their respective fire dances. Such situations affect the sustenance of Baining rituals and their performances. Despite influences on their cultural life, the Baining continue to maintain secrecy over their performances and uphold the cultural knowledge that they rightfully own.

\section{Impact in hybridised settings}

As the demand for the Baining fire dance increases, more performances are now seen in new performance spaces. Outsiders, mainly tourists, are prepared to pay between PGK500 and PGK1,000 to view and document the fire dance. This causes competition amongst the local Bainings, who modify and create new designs on their masks to attract greater attention. Amidst this process, copying of another clan's mask designs became an issue, which resulted in disunity at the village level. Many of these situations are not easily resolved and lead to serious consequences such as death or other misfortunes. According to Jonah Todi Irka, some church groups have led discussions to eliminate the fire dance from ever appearing in any settings at all, whether in the village or in shows and festivals. This action by religious groups was prevalent in the 1980s up until the present, and the main groups of people affected were the Kairaks in the central Baining area. A good number of fire dance masks there were destroyed and banned from performing. However, in the north and south Baining area, the fire dance culture is still very strong and continues to be intact with active ritual performances taking place today. 


\section{Baining discontent}

Given the negative attitude by the coastal Tolai who even today regard the Baining as inferior, the Baining were conscious of the difficulties they were getting themselves into by coming out of their mountain homes and exposing themselves and their culture for others to see. By doing so, they were sometimes being mocked and laughed at because of their appearance. These jokes and derogatory comments were usually made by the Tolai, who were then joined by other spectators as well. This affected their performances as they took offence to these comments and jokes, causing them to shorten or stop their dances abruptly. Sometimes the Baining refused to perform at all, especially during mask festivals. An example is the 2006 National Mask Festival held in East New Britain Province, where spectators threw items such as coconut shells into the fire, which thereby burnt the fire dancers' feet. Other items thrown into the fire during the fire dance performance were inappropriate wood and stones. These materials caused problems as they did not burn well and, as a result, the performers could not dance on them. The stones were even more of a problem as they created sparks in the fire. Following this incident, the Baining refused to perform in any festivals within the province. They complained to the festival authorities and boycotted all subsequent National Mask Festivals.

\section{The fire dance becomes a political issue}

The non-participation of Baining dancers at the National Mask Festival became a concern at the provincial level as it did not promote the goals of the festival. Without the performance of the Baining, there was an imbalance in cultural representation within the province.

After some time, the Baining approached the Festival Organising Committee to resolve this problem. However, the committee was unable to resolve the problem, so the Baining went to the East New Britain Provincial Administration through their local member. A number of consultations were then held between the Baining, the Festival Committee, and the East New Britain Provincial Administration 
(Jacob Simet, ${ }^{1}$ interview, 2015). In the discussions between the three parties, the Festival Committee was interested in getting the fire dance back into the National Mask and Warwagira Festival programme. The East New Britain Provincial Administration wanted the complaints of the Baining to be addressed and resolved. Based on their status as a minority group in the province, the provincial administration made a firm decision that the Baining needed their support. Given this scenario, the concerns of the Baining had become a political issue.

\section{Re-emergence and sustenance}

Following the decision of the East New Britain Provincial Administration to have the Baining included in the National Mask and Warwagira Festival again, the Baining wasted no time in gaining support from other Baining groups in the province. They held meetings with the other Baining to come up with their terms and conditions to represent a united Baining voice to govern and protect their performances from discrimination and abuse. They emphasised that there would be no further display of Baining culture of any sort in the festival unless these issues were properly addressed. In these discussions, the Baining went beyond the matter of fire dance appearances during the festival and raised the issue of the sacredness and nature of their dance, which was open for violation over the years from spectators, and the need to protect and respect the fire dance.

Further, the Baining raised the issue of the way the fire dance was being promoted by tourism organisations both nationally and internationally with no benefits coming back to them. They felt that they had a right to some of the monetary gains from the use of their cultural property.

In the consultations it appeared that the Baining had elevated their fire dance to the position of being their 'symbol of ethnic identity'. As they had very little else to bargain with for recognition from the East New Britain Provincial Government and the dominant coastal Tolai, this cultural item was their only bargaining chip. After these discussions on the fire dance, the Baining started talking about putting a stop to any further demands by the Tolai onto their land. They have been successful in their quest to claim ownership over their land as reported by Isaac Nicholas:

1 Former Executive Director of the National Cultural Commission and member of the National Mask and Warwagira Festival Committee. 
Landowners in East New Britain Province have won a landmark legal battle to retake their 'hijacked' land from the controversial Special Agriculture and Business Lease (SABL). The people of Baining in Gazelle district had taken the State and developer to court over the SABL deal which has now been declared null and void by the National Court in Kokopo last Thursday. (Nicholas 2016)

The above news is timely for the bulk of the Baining people who have fought hard for recognition as the original inhabitants of the Gazelle area in East New Britain Province. As the original settlers in the province, they had the upper hand in these discussions. The Baining in the end decided that they would ban all their groups from further participation in the National Mask and Warwagira Festival in Kokopo or Rabaul. However, they wanted the fire dance to be still part of the festival, but to be staged inside their own territory rather than outside. They advised that henceforth the fire dance would be performed at Gaulim village, during the period of the National Mask and Warwagira Festival. Gaulim village used to be deep inside Baining territory, but due to Tolai encroachment over the years, this village is now on the border of Tolai and Baining territory. The Baining themselves were comfortable with this arrangement.

The National Mask and Warwagira Festival Committee accepted the Baining decision half-heartedly, but this was the only option they had. They were content with the fact that at least the fire dance would continue to be part of the festival. Logistical arrangements had to be made between the festival committee and the tour operators to facilitate the patronage of tourists wanting to observe the fire dance at Gaulim village. Two main issues that the committee was prepared to assist with were transportation and security to the venue. The parties also agreed that the Baining could charge a fee per head to tourists.

As a result of this arrangement, the Baining now organise the fire dance at Gaulim village during the period of the National Mask and Warwagira Festival. The festival committee and the tour operators of East New Britain organise the transportation and security for tourists who go to the village. Arrangements are made between the tour operators and the Baining for bookings to be made and fees to be paid by the tour operators to the Baining organisers of the fire dance. According to Jacob Simet and Jonah Todi Irka, this arrangement has been in place for at least five years with the increase in number of tourists going to Gaulim during the festival period. Both interviewees (Simet and Irka) continue to observe that some other 
Baining dances and performances have begun to reappear at the National Mask and Warwagira Festival in Kokopo, but the fire dance remains in the Baining territory (see Figure 5).

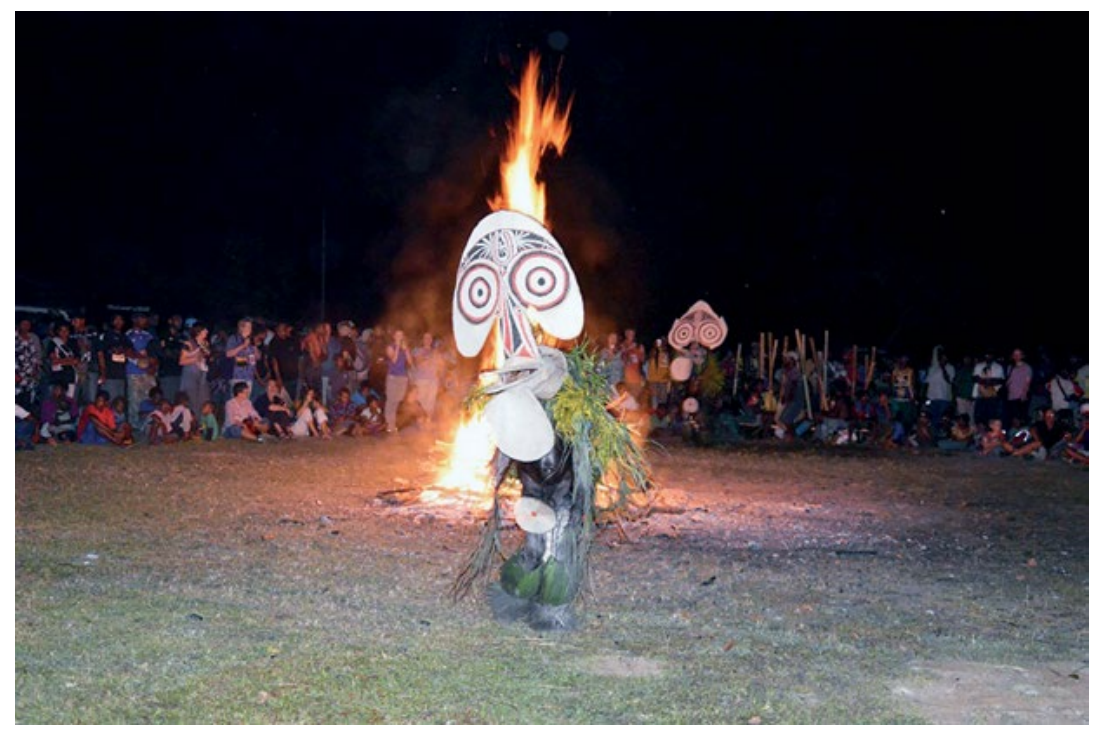

Figure 5. Baining fire dancer, National Mask Festival, Gaulim area, central Baining, July 2015

Source: Gedisa Jacob

\section{Conclusion}

The fire dance has been and continues to be researched extensively by anthropologists, priests, and other researchers who have documented and published on the rich culture and history of the Baining. This chapter has referenced the accounts of Fajans (1985) and Hesse and Aerts (1996 [1982]) on the Baining's rich traditions. Both accounts captured aspects of the fire dance and its relation to the Baining's belief systems. Given their perceived inferiority when compared to the Tolai, the Baining have persevered to claim and protect their identity using the Baining fire dance as a traditional iconic performance to gain attention as being different and special from the Tolai.

Over the years, Baining masks and the fire dance have intrigued various spectators and led to their popular appearances in local and international shows. The demand on the Baining fire dance has been noticed by many 
locals, especially at the local and provincial level, who have occasionally interrupted and mocked their performances during festivals held in East New Britain Province. The latest action by the Baining to protect their performance of the dance, have it relocated to Gaulim, and have tourists and other audience members travel up to the central Baining area to view its performance is a statement in itself, further demarcating their identity as distinct from the Tolai.

Moving into the twenty-first century, fire dance performances remain complicated areas for study. The full essence of the dance can only be understood and appreciated locally and politically when its people are respected and valued as being the original inhabitants of East New Britain Province.

\section{References cited}

Fajans, Jane. 1985. 'They Make Themselves: Life Cycle, Domestic Cycle and Ritual among the Baining.' PhD diss., Stanford University.

Hesse, Karl, and Theo Aerts. 1996 [1982]. Baining Life and Lore. Rev. ed. Port Moresby: University of Papua New Guinea Press.

Lewis, M. Paul, Gary F. Simons, and Charles D. Fennig. 2013. eds. Ethnologue: Languages of the World. 17th ed. Dallas: SIL International. Online version: www.ethnologue.com.

Nicholas, Isaac. 2016. 'Bainings Win SABL Court Battle'. ACTNOW $B \log$ (30 August). actnowpng.org/blog/blog-entry-bainings-win-sablcourt-battle. 
This text is taken from A Distinctive Voice in the Antipodes: Essays in Honour of Stephen A. Wild, edited by Kirsty Gillespie, Sally Treloyn and Don Niles, published 2017 by ANU Press, The Australian National University,

Canberra, Australia.

dx.doi.org/10.22459/DVA.07.2017.09 